\title{
Linear and Nonlinear Ultrasonic Properties of Granular Soils
}

B.P. Bonner, P.A. Berge, C.M. Aracne-Ruddle, H. BerteteAguirre, D. Wildenschild, C.N. Trombino and E.D. Hardy

This article was submitted to the

Materials Research Society Meeting

San Francisco, $C A$

April 24-28, 2000

U.S. Department of Energy

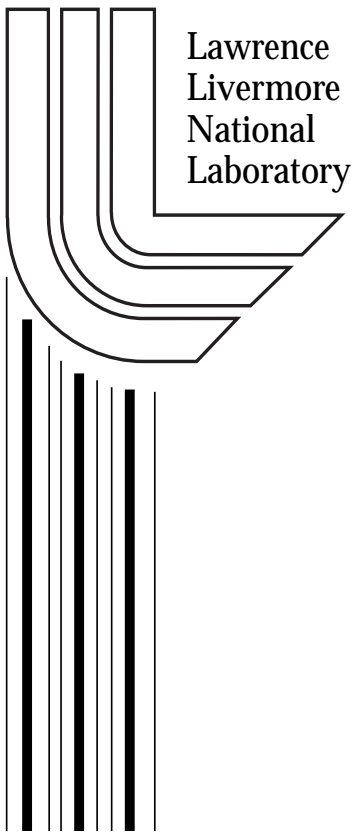

April 20, 2000 


\section{DISCLAIMER}

This document was prepared as an account of work sponsored by an agency of the United States Government. Neither the United States Government nor the University of California nor any of their employees, makes any warranty, express or implied, or assumes any legal liability or responsibility for the accuracy, completeness, or usefulness of any information, apparatus, product, or process disclosed, or represents that its use would not infringe privately owned rights. Reference herein to any specific commercial product, process, or service by trade name, trademark, manufacturer, or otherwise, does not necessarily constitute or imply its endorsement, recommendation, or favoring by the United States Government or the University of California. The views and opinions of authors expressed herein do not necessarily state or reflect those of the United States Government or the University of California, and shall not be used for advertising or product endorsement purposes.

This is a preprint of a paper intended for publication in a journal or proceedings. Since changes may be made before publication, this preprint is made available with the understanding that it will not be cited or reproduced without the permission of the author.

This report has been reproduced directly from the best available copy.

Available to DOE and DOE contractors from the

Office of Scientific and Technical Information

P.O. Box 62, Oak Ridge, TN 37831

Prices available from (423) 576-8401

http:/ / apollo.osti.gov/bridge/

Available to the public from the National Technical Information Service

U.S. Department of Commerce 5285 Port Royal Rd., Springfield, VA 22161 http://www.ntis.gov/

OR

Lawrence Livermore National Laboratory Technical Information Department's Digital Library http://www.llnl.gov/tid/Library.html 


\title{
Linear and Nonlinear Ultrasonic Properties of Granular Soils
}

\author{
Brian P. Bonner, Patricia A. Berge, Chantel M. Aracne-Ruddle, Hugo Bertete-Aguirre, \\ Dorthe Wildenschild, Cosette N. Trombino, and Edgar D. Hardy \\ Experimental Geophysics Group, Lawrence Livermore National Laboratory, \\ L-201, PO Box 808, \\ Livermore, CA 94551-9900, U.S.A.
}

\begin{abstract}
The ultrasonic pulse transmission method (100-500 kHz) was adapted to measure compressional (P) and shear (S) wave velocities for synthetic soils fabricated from quartz-clay and quartz-peat mixtures. Velocities were determined as samples were loaded by small (up to 0.1 $\mathrm{MPa}$ ) uniaxial stress to determine how stress at grain contacts affects wave amplitudes, velocities, and frequency content. Samples were fabricated from quartz sand mixed with either a swelling clay or peat (natural cellulose). P velocities in these dry synthetic soil samples were low, ranging from about 230 to $430 \mathrm{~m} / \mathrm{s}$ for pure sand, about 91 to $420 \mathrm{~m} / \mathrm{s} \mathrm{for} \mathrm{sand-peat}$ mixtures, and about 230 to $470 \mathrm{~m} / \mathrm{s}$ for dry sand-clay mixtures. S velocities were about half of the $P$ velocity in most cases, about 130 to $250 \mathrm{~m} / \mathrm{s}$ for pure sand, about $75-220 \mathrm{~m} / \mathrm{s}$ for sand-peat mixtures, and about $88-220 \mathrm{~m} / \mathrm{s}$ for dry sand-clay mixtures. These experiments demonstrate that $\mathrm{P}$ and $\mathrm{S}$ velocities are sensitive to the amount and type of admixed second phase at low concentrations. We found that dramatic increases in all velocities occur with small uniaxial loads, indicating strong nonlinearity of the acoustic properties. Composition and grain packing contribute to the mechanical response at grain contacts and the nonlinear response at low stresses.
\end{abstract}

\section{INTRODUCTION}

Wave propagation in natural granular media applies to a range of problems in near-surface geophysics and environmental engineering. Earthquake strong motion, observations of ground water movement using seismic methods and slope stability problems in civil engineering are some examples. Interest in these problems has generated an extensive literature on elastic properties of natural granular media [1], but experimental difficulties have prevented measurements at the very low pressures corresponding to the shallow subsurface. New experimental methods were developed to accomplish the measurements reported here [2]. Although these methods can be used for natural materials recovered from in-situ, first experiments were conducted on synthetic soils so that critical parameters such as composition, porosity, and packing technique could be controlled and investigated systematically.

\section{EXPERIMENTAL DETAILS}

The experimental method is ultrasonic pulse transmission, modified for measurements in highly attenuating materials [3]. The time-of-flight of an ultrasonic pulse launched from a transmitting to a receiving transducer and the sample length $(44.9 \mathrm{~mm})$ yields the velocity for $\mathrm{P}$ 
and $\mathrm{S}$ waves as appropriate. Changes in the path length produce small changes in travel time compared to concurrent stress-induced changes in the elastic constants and are neglected here in velocity computations. Transducers with center frequencies ranging from 100 to $500 \mathrm{kHz}$ polarized for transverse shear were used for S measurements, although sufficient compressional energy is available for simultaneous P measurements. Further improvements on previous methods [3] were made to allow measurements of highly attenuated signals. The transmitting

transducer was excited with $400 \mathrm{~V}$ pulses. Received signals were as small as $10^{-5} \mathrm{~V}$, requiring amplification of $60 \mathrm{db}$ for detection and digital averaging of 200-1000 repetitions to pick arrivals. A sample sleeve was constructed to ensure that the signal travels through the soil mixture, suppressing energy traveling on longer, but faster, paths to the receiving transducer [2]. The sample assemblies were closed with latex membranes that transmitted sound from the transducer and contained the soil mixture. Accuracy was limited to $20 \%$ at the lowest stresses but improved with signal amplitude to $\sim 3 \%$ for compressional waves and $10 \%$ for shear waves at higher stresses. Some of the data scatter is caused by differences in subjective picking of arrivals, as well as dramatic changes in the character of the waveforms with stress.

End-load pressures between 0 and 15 psi ( 0 to $0.11 \mathrm{MPa})$, simulating up to several meters of overburden, are applied in increments of approximately 1.5 psi to the sample by air-driven, pneumatic pistons that push on the transducer housing. Internal stress in the sample approximates uniaxial strain, modified by edge effects and minor sleeve deformation.

Samples were constructed by mixing pure quartz sand with either clay or peat moss in increasingly larger percentages by weight. The sand (Ottawa, IL) and was sieved to a median grain diameter of 273 micrometers. The clay is Na-montmorillonite from Wyoming, a swelling smectite. The clay is equilibrated in a $100 \%$ humid atmosphere for seven days before sample preparation to achieve reproducible water content. The peat is commercial Canadian sphagnum peat moss, composed mainly of natural cellulose fibers. Typical organic content of peat moss is 80 to $95 \%$ of the mass fraction. The peat was equilibrated with air at ambient humidity, typically $30 \%$, before sample construction. The samples were layered to include a central section of pure sand to be consistent with earlier experiments that required a high permeability layer to provide access for pore fluid. Measured travel times were corrected to allow for the sand layer, using data from a sand sample prepared using the same methods as used for the mixtures. Velocities, attenuation and load dependence are sensitive to the packing methods (vibration, hand packing) used in sample fabrication for the low stress levels of these experiments. Packing effects contribute to the scatter observed in experimental data.

\section{RESULTS}

Representative waveforms for sand-clay mixtures are presented in figure 1 to give a general idea of the quality of the data and to demonstrate the dramatic effects of external loading on transmitted pulses. Complete data sets are archived elsewhere [4,5]. Three waveforms plotted at the same scale (zero gauge units, 7.8 and $15.6 \mathrm{psi}$ ) for the 10\% clay-sand sample are shown in figure 1. Both the compressional and shear waves arrive earlier with increasing load. The compressional amplitude increases only slightly, if at all. The shear amplitude increases with increasing load and also becomes sharper, consistent with a decrease in shear attenuation and more efficient transmission of high frequencies.

Velocities for sand-clay and sand-peat mixtures are plotted in figure 2 to demonstrate that velocities are low and can increase rapidly with small static loads. Two different pure sand 


\section{0\% Na-Montmorillonite Clay with F-50 Ottawa Sand - Dry}

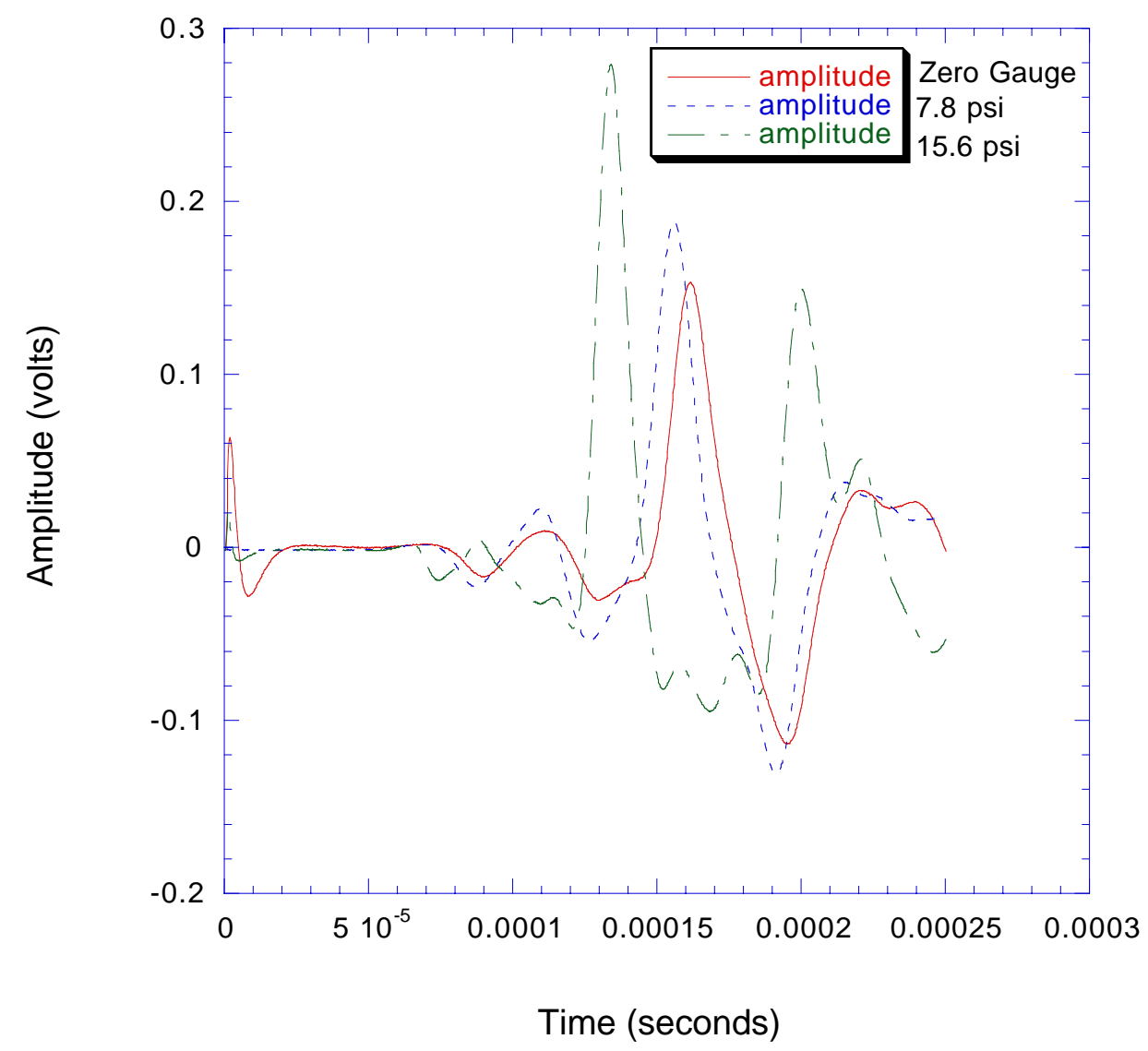

Figure 1. Waveforms for 10\% clay, 90\% sand sample for three different load values

samples were examined; one after packing by vibration and the other after hand packing. Vibration produces higher velocities and smaller velocity increases with increasing load. All mixtures were hand packed. Adding clay to the sand increases compressional velocity relative to the hand-packed sand sample and eliminates the velocity increase with pressure at low load. Although trends are less clear for the shear velocity, added clay increases velocity and tends to suppress the gradient to the highest loads. Measurements for sand-peat mixtures were generally more difficult and show more scatter because of sample variability and high ultrasonic attenuation. Adding peat to sand decreases compressional and shear velocity, except for the $60 \%$ sample, which shows the highest $\mathrm{P}$ velocity. Peat mixtures show velocity gradients comparable to hand-packed sand, except for the anomalous $60 \%$ peat sample. 

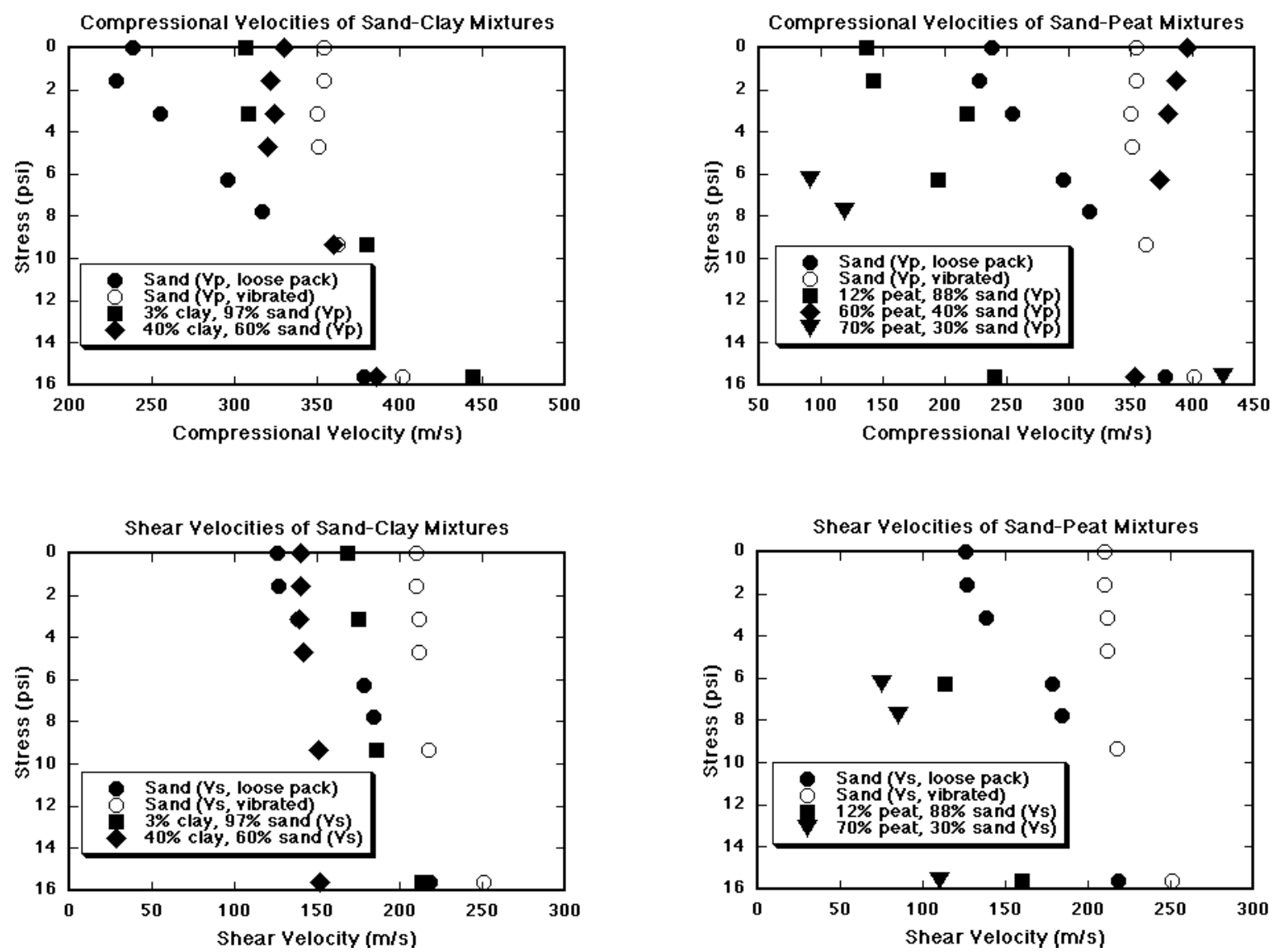

Figure 2. Compressional and shear velocities for sediments as a function of uniaxial load

\section{DISCUSSION AND CONCLUSION}

Although the behaviors shown in figure 2 are complicated, several dominant trends are evident. Packing technique dominates velocity gradient effects. The stress sensitivity of the sand velocities is altered by the addition of small amounts of clay for loosely packed samples. For these samples, compressional velocity of sand-clay at all concentrations is essentially constant until the stress exceeds 8 psi, at which point $P$ velocity increases at a rate similar to the pure sand. It appears that the clay binds the sand grains until a critical stress is exceeded, and then yields and flows away from regions of local high stress at grain contacts. This behavior appears to persist to the highest clay fraction tested, $40 \%$ clay. Compressional velocity gradients of the peat mixtures are variable, and will be investigated further in additional experiments. The anomalous behavior of the $60 \%$ peat sample coincides with the elimination of air-filled porosity at that concentration. Discussion of the effects of microstructural parameters and modeling these results with effective medium theories is presented elsewhere [6].

The velocities observed for the synthetic soils tested in this study are low, with a compressional velocity comparable to the sound speed in air for the slowest sand-peat mixtures. The compressional velocities are lower than typical field values [1] and are slightly higher than 
values for near-surface sand in situ [7]. The admixed second phase can alter seismic attributes even for low mass-fractions. The photomicrograph of $90 \%$ sand, $10 \%$ clay spread on a glass slide shown in figure 3 suggests that the micromechanics of the small clay particles may explain this strong influence. The clay particles adhere electrostaticly to the quartz grains, with their long axes perpendicular to the surface, and tend to bridge the gaps between quartz grains. The large increase in compressional velocity when clay is first added to sand, accompanied by a decrease in shear attenuation, suggests that the clay alters the grain contacts by acting as an adhesive. The packing effects obscure the dependence of velocities on the presence of the second phase, for our sand-clay mixtures. We do not see monotonic increases in velocities as more clay is added.

In contrast, peat does not increase the velocity at low concentrations; instead, even in small amounts, peat causes both $\mathrm{P}$ and $\mathrm{S}$ velocities to decrease. Packing is less important for the sandpeat samples than for the sand-clay samples. As peat is added to sand, this soft second phase disrupts the structure of the sand framework, causing a decrease in velocity. As the mass fraction of the second phase continues to increase, porosity reduction dominates, generally producing the highest velocities. Finally, when the free porosity is eliminated, velocities begin to drop as the slow second phase becomes the framework. This behavior is similar to that reported for sand-kaolinite mixtures at high pressures [8].

The pressure dependence of the ultrasonic attributes indicates that wave transmission is extremely sensitive to the details of stress transmission through granular media. The nonlinear behavior of the elastic properties is an effective probe of conditions at grain contacts, which are fundamental to understanding the granular state.

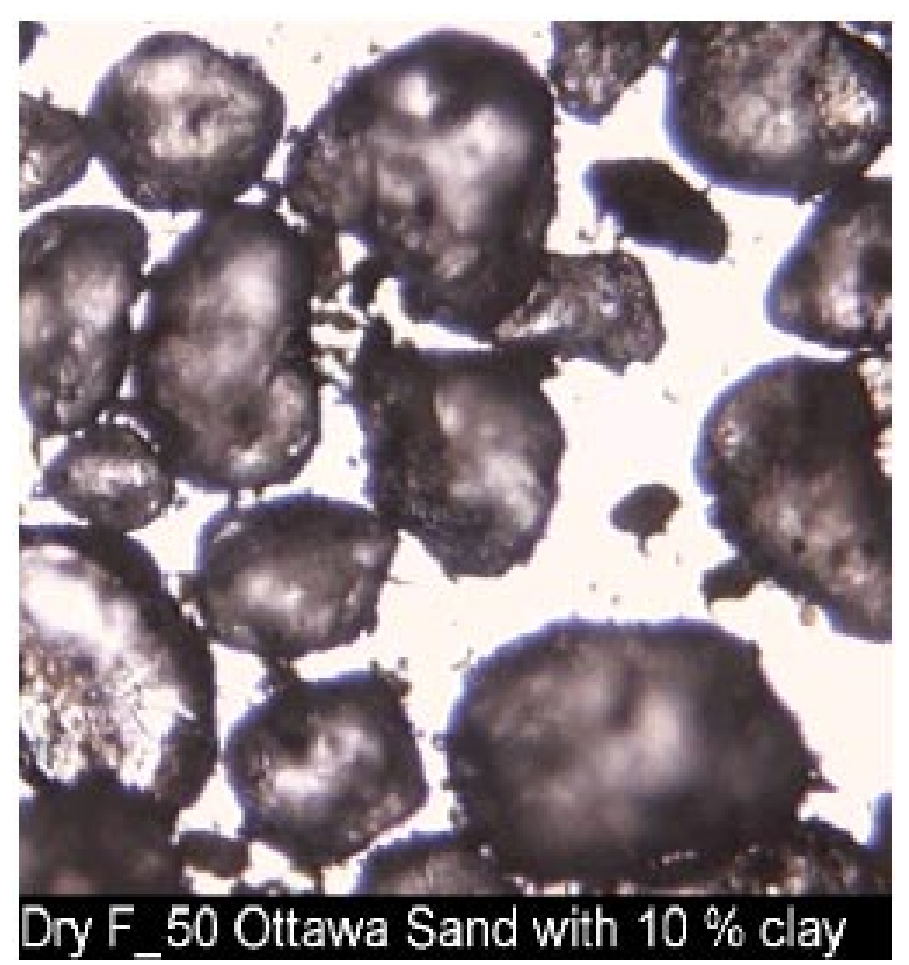

Figure 3. Photomicrograph of $90 \%$ Ottawa sand (mean grain diameter 270 microns) and 10\% Wyoming bentonite 


\section{ACKNOWLEDGMENTS}

D. Hart and C. Rowe made initial measurements and helped with experimental design. C. Boro designed and constructed the ultrasonic and loading assembly. This work was performed under the auspices of the U.S. Department of Energy by the University of California Lawrence Livermore National Laboratory under contract number W-7405-ENG-48 and supported specifically by the Environmental Management Science Program of the DOE Office of Environmental Management and the Office of Science.

\section{REFERENCES}

1. Bourbie, T., O. Coussy, and B. Zinszner, Acoustics of Porous Media (Gulf Publishing, 1987) $334 \mathrm{pp}$.

2. Bonner, B. P., C. Boro, and D. J. Hart, Anti-waveguide for ultrasonic testing of granular media under elevated stress, LLNL Patent disclosure IL-10607, and patent application, DOE Patent Docket No. S-94182 (1999).

3. Sears, F. M., and B. P. Bonner, Ultrasonic attenuation measurement by spectral ratios utilizing signal processing techniques, IEEE Trans. On Geoscience and Remote Sensing, GE-19, 95-99 (1981).

4. Aracne-Ruddle, C. M., B. P. Bonner, C. N. Trombino, E. D. Hardy, P. A. Berge, C. O. Boro, D. Wildenschild, C. D. Rowe, and D. J. Hart, Ultrasonic velocities in unconsolidated sand/clay mixtures at low pressures, LLNL report UCRL-JC-135621, Lawrence Livermore National Laboratory, Livermore, CA (1999).

5. Trombino, C. N., Elastic properties of sand-peat moss mixtures from ultrasonic measurements, LLNL report UCRL-ID-131770, Lawrence Livermore National Laboratory, Livermore, CA (1998).

6. Berge, P. A., J. G. Berryman, B. P. Bonner, J. J. Roberts, and D. Wildenschild, Comparing geophysical measurements to theoretical estimates for soil mixtures at low pressures, LLNL report UCRL-JC-132893, Proceedings of the Symposium on the Application of Geophysics to Engineering and Environmental Problems, ed. M. H. Powers, L. Cramer, and R. S. Bell, March 14-18, 1999, Oakland, CA, Environmental and Engineering Geophysical Society, Wheat Ridge, CO (1999) pp. 465-472.

7. Bachrach, R., J. Dvorkin, and A. Nur, High-resolution shallow-seismic experiments in sand, Part II: Velocities in shallow unconsolidated sand, Geophysics, 63, 1233-1240 (1998).

8. Marion, D., A. Nur, H. Yin, and D. Han, Compressional velocity and porosity in sand-clay mixtures, Geophysics, 57, 554-563 (1992). 